\title{
Immunological disturbances in myasthenia gravis with a report of Hashimoto's disease developing after thymectomy ${ }^{1}$
}

\author{
JOHN A. SIMPSON \\ From the Department of Medicine, Edinburgh University, and the Neurological Unit, Northern General \\ Hospital, Edinburgh
}

During the years 1953-55 I was privileged to examine a large number of patients who had been treated for myasthenia gravis at the National Hospital and other centres in London. The survey was made in order to evaluate the efficacy of thymectomy in the treatment of that disease. In reviewing the results it was remarked that myasthenia gravis was a favourite subject for the demonstration of the physiological mechanisms in disease yet, despite a period of unprecedented advances in knowledge of the physiology of the neuromuscular junction, the nature of the myasthenic response remained unknown. None of the theories current at that time attempted to account for the facts of thymic pathology and of clinical response to thymectomy. The role of surgery was indeed still debated, but the review showed that there was a statistically significant benefit to a myasthenic patient provided that the thymus was removed within five years of the onset of symptoms (Simpson, 1958). This temporal limitation is difficult to account for if the thymus is producing a 'curare-like' substance as ordinarily understood.

It was decided to approach the problem without bias by recording as fully as possible the medical history of each patient interviewed. No clinical fact was rejected on grounds of apparent irrelevancy. When the assembled data on 440 cases were reviewed (the London series supplemented by the first 33 of a personal series in Glasgow and Edinburgh) some surprising observations were made. First it was found that a few cases had evidence of temporary disturbance of the central or peripheral nervous system and supporting cases were found in the literature. No particular non-muscular disease appeared to be related closely to myasthenia apart from disorders of the thyroid gland. Nevertheless certain disorders of the blood, reticulo-endothelial system, and joints were noted. At that time a working hypothesis was

'This paper was read at the St. Andrew's Day symposium of the Royal College of Physicians of Edinburgh, on 7 December 1963. considered, namely, that myasthenia gravis was only the most prominent feature of a disorder which could occasionally involve other organs. The age distribution, the high incidence in females, and the natural history of the disease were suggestive of a pathological process resembling systemic lupus erythematosus. Furthermore it was known that myasthenia gravis may occasionally complicate systemic lupus erythematosus (Harvey, Shulman, Tumulty, Conley, and Schoenrich, 1954; and the author's series).

In Glasgow in 1955, Dr. J. R. Anderson kindly helped me to attempt to produce myasthenia in mice by inoculation of homologous muscle with Freund's adjuvant, but we had no success. (This could not be mentioned by Simpson at the time (1960) as the Honyman-Gillespie lecturer is forbidden to discuss animal experiments.) Nevertheless the concept seemed to account for more details of the disease than any hitherto available though it involved the assumption that the thymus did not function as an endocrine gland in the usual sense but as a reticuloendothelial organ which was important in immunity reactions, probably the first suggestion of this role. During the next three years the concept of autoimmunity as a mechanism in disease was gaining ground. My conviction that it was a factor in myasthenia gravis was increased when in 1959 Smithers remarked that the histological changes in the thymus were suggestive of an autoimmune process and Nastuk, Strauss, and Osserman (1959), while searching for a neuromuscular blocking substance, found that blood from myasthenic patients sometimes caused lysis of frog muscle cells. A lesser degree of cytolysis was caused by blood from some normal subjects. They then examined the activity of serum complement. In most myasthenic patients it was within the normal range but in a few cases it was either high or far below normal and this tended to correlate with remissions and exacerbations respectively (Nastuk, Plescia, and Osserman, 1960). 
Though Smithers (1959) did not suggest how the muscle disease could be caused and the American team did not consider a role for the thymus, their independent evidence encouraged me to formulate a hypothesis which was described in a HonymanGillespie lecture in April 1960. It was suggested that the thymus might stimulate the production of lymphocytes carrying antibody against the endplate protein of muscle, and possibly also against muscle fibres, nerve endings, and on occasion the central nervous system and other organs such as the bone marrow and the joints, in close analogy with systemic lupus erythematosus. It was shown that an antibody could act as a neuromuscular blocking substance of 'competitive' type which would account for the myasthenic phenomenon. (The American cytolytic theory does not explain the reversible nature of the weakness.) Furthermore, an antibody against muscle could account for the facts that a baby born to a myasthenic mother may have temporary myasthenia, yet transfusion of blood from a myasthenic patient into another adult does not cause myasthenic signs. Coincident with the publication of this lecture (Simpson, 1960), Strauss, Seegal, Hsu, Burkholder, Nastuk, and Osserman (1960) demonstrated the presence of a muscle-binding globulin in myasthenic serum and this has been confirmed by Beutner, Witebsky, Ricken, and Adler (1962) and Feltkamp, van der Geld, and Oosterhuis (1963b). These authors describe four different types of reaction of globulin to muscle based on immunofluorescence techniques: (1) fluorescence of the sarcolemma, which also occurs with control sera; (2) fluorescence of the A bands of muscle fibres; (3) similar involvement of only about half of the muscle fibres ('zebra' type); and (4) nuclear fluorescence. Only types (2) and (3) seem to be specific for myasthenia gravis. There is not at present any direct evidence for an antibody confined to the endplate zone such as I had postulated, nor to the nerve terminals which was suggested as an alternative. A further search should be made for these as the present evidence suggests that the antibodies against the muscle fibres only occur in significant quantity in the presence of a thymic tumour (vide infra). The nuclear fluorescence is due to the presence of antinuclear factor in the serum (Feltkamp, van der Geld, Kruyff, and Oosterhuis, 1963a).

The response to the autoimmune hypothesis was immediate. Marshall and White (1961) showed that direct injection of bacterial antigen into the guineapig thymus produced a histological reaction which was essentially the same as that seen in myasthenia gravis. Their studies suggested that a blood-thymus barrier exists which would preclude any cellular reaction of the normal thymus to circulating antigen

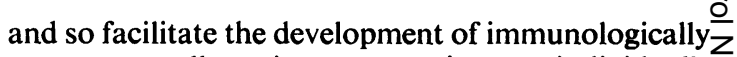
competent cells active even against an individual's $s$ own tissues. By this time experimental biologistsô were coming to the conclusion that the thymuse played a very important role in the development of immunological response (Miller, 1961, 1963; Burnet, ${ }_{\text {, }}$ $1962 \mathrm{a}, \mathrm{b})$. It seems very likely that immunological mechanisms are disturbed in myasthenia gravis. It remains to be demonstrated whether they are causa $-\frac{2}{2}$ tive or not.

One question which immediately arises is whetherô the immunological response is organ and species-o specific. The cytolytic effect described by Nastuko et al. (1959) on frog muscle, and the globulin $\overline{\bar{s}}$. binding on human and rat skeletal muscle (Strausso et al., 1960; Feltkamp et al., 1963a, b) demonstraten that the antibodies are not species-specific. Strauss et al. (1960) found that the globulin which binds to $\overrightarrow{0}$ skeletal muscle does not do so with cardiac or $\overrightarrow{-}$ uterine muscle and they also had negative resultso against thymus tissue obtained from two myasthenic patients. The reaction was shown to cause fixation ofo complement. Their positive results were obtained from the pooled sera of 10 myasthenic patients, of whom six had a thymoma. Many others investigated showed no muscle-binding globulin in their seruin. Beutner et al. (1962) confirmed their results wịt sera from two of 10 myasthenic patients. Both sega which were obtained from the only cases withor thymoma, also showed fluorescence with heart muscle by the direct and indirect fluorescent anfi $\mathrm{i}$ body techniques, but the complement-fixing a de staining technique using heart tissue was negative The presence of at least two antibodies is suggested one specific to skeletal muscle and the other reacting with skeletal and cardiac muscle. Van der Geld ancb Oosterhuis (1963), using an antiglobulin consump ș tion test with or without the aid of immunoelectro. phoresis, found that $40 \%$ of sera containing antio bodies reacting with skeletal muscle also reacted with thymus. They did not encounter sera with anti $\overrightarrow{0}$ bodies acting exclusively against thymus. Cross 3 absorption experiments suggested that there were two distinct circulating antibodies, one of which reacted with skeletal muscle or thymus, the othes with skeletal muscle alone. No reaction was found with heart, liver, pancreas, or kidney tissues. The incidence of anti-muscle antibodies was consistently. higher in cases with thymoma (van der Geld, Felt? kamp, Loghem, Oosterhuis, and Biemond, 1963B and this may account for our failure to find cono vincing evidence of anti-muscle antibodies since there were no patients with thymoma in the small series investigated. It would be interesting to examine the correlation between muscle antibodies of the Strauss type and the atrophic muscular weakness found in 
some myasthenics which does not respond to anticholinesterase drugs. This 'myasthenic myopathy' was not a feature of the cases I examined for muscle antibodies. It is more common in cases associated with a thymoma though not confined to them (Simpson, 1958).

Burnet (1962b) classified myasthenia gravis in his group I (organ-specific) type of autoimmune disease while acknowledging that a possible relationship with rheumatoid arthritis might necessitate revision of this provisional classification. This putative relationship was based on the present author's paper (see Burnet, 1962a). In the original report (Simpson, 1960) the disorder was listed as 'rheumatoid' arthritis to indicate that it resembled true rheumatoid arthritis but might differ from it. This was done because the arthropathy affected the small joints (Fig. 1) but was sometimes transitory. Van der Geld et al. (1963) have recently reported that the rheumatoid factor was present in the serum of five of $111(4.5 \%)$ cases of myasthenia gravis (Tables I and II). Six patients in their series had rheumatoid arthritis (sic), but it seems from a letter by Feltkamp et al. (1963a) that only one of these patients had the rheumatoid factor in the blood so it would appear that the other positive findings were
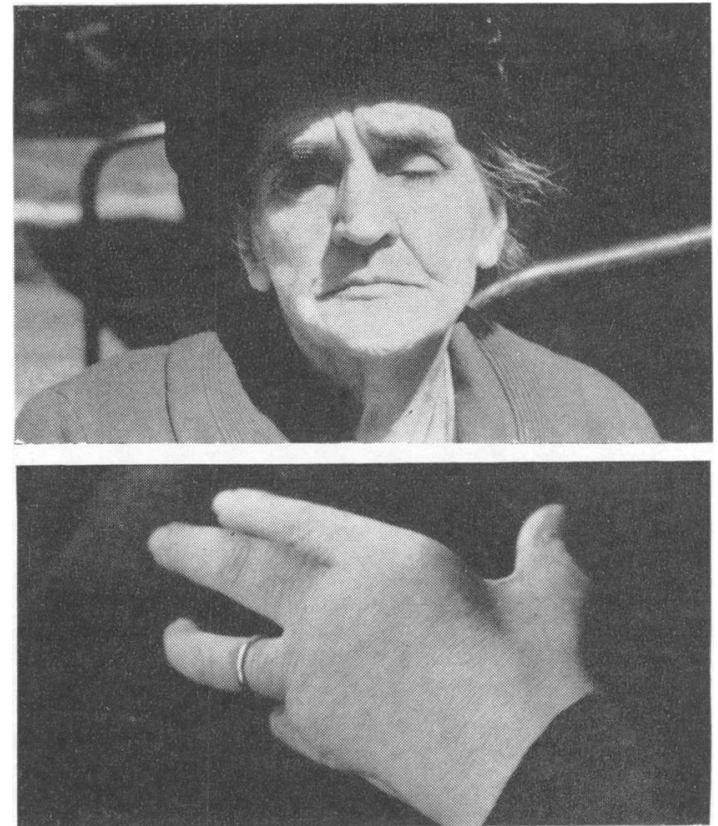

FIG. 1. Arthropathy of metacarpo-phalangeal joints in a case of myasthenia gravis.

TABLE I

DISORDERS ASSOCIATED WITH MYASTHENIA GRAVIS

\begin{tabular}{|c|c|c|c|c|c|}
\hline Present & $i^{1} s^{1}$ & Osserman & Storm-Mathisen & White and Marshall & Van der Geld \\
\hline London & Scorland & & & & \\
\hline
\end{tabular}

\begin{tabular}{|c|c|c|c|c|c|c|}
\hline Thyroid (all types) & 72 & $15^{2}$ & 17 & 5 & 3 & 11 \\
\hline Diabetes and glycosuria & 9 & 7 & 8 & & 1 & \\
\hline 'Rheumatoid' arthritis & 12 & 6 & 15 & 3 & 2 & 6 \\
\hline Systemic L.E. & 1 & & & & $\overrightarrow{1}$ & \\
\hline Cutaneous L.E. & & & & & 1 & \\
\hline Sarcoidosis & 1 & & & & & \\
\hline Red cell aplasia & 1 & & & & & \\
\hline Pernicious anaemia & 1 & 8 & & & & \\
\hline Haemolytic anaemia & & $2^{3}$ & & 1 & & \\
\hline Hepatitis & & $2^{3}$ & 2 & & & \\
\hline Nephritis & 2 & & 1 & $1(?)$ & & \\
\hline Raynaud's syndrome & 10 & 6 & & & & \\
\hline Epilepsy and 'blackouts' & 5 & 6 & 2 & & & \\
\hline Psychosis & 9 & 1 & 14 & 4 & & \\
\hline Patients & 407 & 84 & 325 & 90 & 15 & 111 \\
\hline
\end{tabular}

TABLE II

ANTIBODIES DETECTED IN SERA FROM PATIENTS WITH MYASTHENIA GRAVIS

$\begin{array}{llllll}\text { Antinuclear } & \text { Rheumatoid } & \text { Muscle } & \text { Thyroid } & \text { Stomach } & \text { Liver } \\ \text { Factor } & \text { Factor }^{2} & & \end{array}$

\begin{tabular}{|c|c|c|c|c|c|c|c|}
\hline \multirow[t]{2}{*}{ Present series } & Positive & 8 & $\mathbf{0}$ & 1 & 10 & 3 & $\mathbf{0}$ \\
\hline & Total & 40 & 8 & 9 & 39 & 38 & 36 \\
\hline White and Marshall (1962) & Positive & 6 & 2 & & 1 & & \\
\hline & Total & $15^{1}$ & 15 & & 15 & & \\
\hline Van der Geld et al. (1963) & $\begin{array}{l}\text { Positive } \\
\text { Total }\end{array}$ & $\begin{array}{r}11 \\
111\end{array}$ & $\begin{array}{r}5 \\
111\end{array}$ & $\begin{array}{l}38 \\
98\end{array}$ & $\begin{array}{r}36 \\
111\end{array}$ & & \\
\hline
\end{tabular}

'One case of carcinomatous myasthenia excluded.

${ }^{2}$ Rheumatoid factor-S.S.C.T. in present series, latex test in others. 
made on myasthenic patients without clinical evidence of arthritis. Arthritis was present in three of 15 cases of myasthenia gravis reported by White and Marshall (1962), and two of these had a positive latex test for rheumatoid factor and hyperglobulinaemia at the time of examination or previously.
One of these was later diagnosed as systemic lupus erythematosus. Antinuclear factor was demonstrated in six of the 15 cases and another two gave positive nuclear fluorescence with undiluted serum. Thyroide tissue was used to detect the presence of antinucleas factor in the serum. The positive reactors included

TABLE III

SUMMARY OF RELEVANT CASES

Antibodies Specific for the Following Tissues

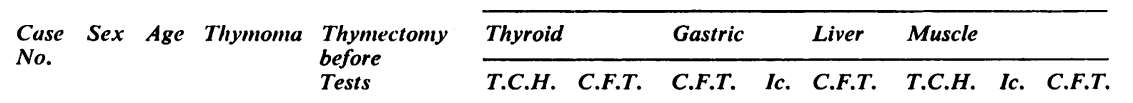

Anti-

S.S.C.T. Associated Conditions

\begin{tabular}{|c|c|c|c|c|c|c|c|c|c|}
\hline 294 & $\mathbf{F}$ & 73 & - & & - & - & - & - & - \\
\hline 3054 & $\mathbf{F}$ & 49 & - & & 25 & - & - & - & - \\
\hline 3231 & $\mathbf{F}$ & 48 & - & & & & & & \\
\hline 3609 & $\mathbf{F}$ & 24 & - & + & & & & & \\
\hline 3912 & $\mathbf{F}$ & 32 & - & + & $\begin{array}{r}250 \\
25\end{array}$ & 32 & 32 & + & - \\
\hline 4301 & $\mathbf{M}$ & 55 & & & - & - & - & - & - \\
\hline 4536 & $\mathbf{F}$ & 22 & - & + & - & - & - & - & - \\
\hline 4585 & $\mathbf{F}$ & 22 & - & + & - & - & - & - & - \\
\hline 4586 & $\mathbf{F}$ & 13 & - & & & & & & \\
\hline 4603 & $\mathbf{F}$ & 8 & - & & & & & & \\
\hline 4611 & $\mathbf{F}$ & 19 & - & & & & & & \\
\hline 4636 & $\mathbf{F}$ & 53 & & & - & 16 & - & - & - \\
\hline 4649 & $\mathbf{F}$ & 48 & & & & & & & \\
\hline 4656 & $\mathbf{F}$ & 30 & & & & & & & \\
\hline 4934 & $\mathbf{F}$ & 32 & - & + & $\begin{array}{r}25 \\
5\end{array}$ & - & $\begin{array}{r}8 \\
16\end{array}$ & + & - \\
\hline 5315 & $\mathbf{F}$ & 27 & - & + & - & - & - & - & - \\
\hline 5401 & $\mathbf{F}$ & 64 & & & & & & & \\
\hline 5409 & $\mathbf{M}$ & 39 & & & - & - & - & - & - \\
\hline 5494 & $\mathbf{F}$ & 78 & & & - & - & - & - & - \\
\hline 5503 & $\mathbf{F}$ & 72 & & & 250 & - & 16 & $t+$ & - \\
\hline 5625 & $\mathbf{F}$ & 21 & & & - & - & - & - & - \\
\hline 5652 & $\mathbf{M}$ & 28 & - & + & - & 16 & $-\cdot$ & - & - \\
\hline 5683 & $\mathbf{F}$ & 38 & & & - & - & - & - & - \\
\hline 5766 & $\mathbf{F}$ & 23 & & + & - & - & - & - & - \\
\hline 6289 & $\mathbf{M}$ & 39 & & & 250 & - & - & - & - \\
\hline 6433 & $\mathbf{F}$ & 14 & - & & - & - & - & - & - \\
\hline 6476 & $\mathbf{M}$ & 50 & + & + & - & - & - & - & - \\
\hline 6481 & $\mathbf{F}$ & 41 & - & & - & - & - & - & - \\
\hline 6503 & $\mathbf{M}$ & 54 & & & - & - & - & - & - \\
\hline 6522 & $\mathbf{F}$ & 57 & + & + & 250 & - & - & - & - \\
\hline 6780 & $\mathbf{M}$ & 65 & & & - & - & - & - & - \\
\hline 6792 & $\mathbf{F}$ & 22 & - & + & - & - & - & - & - \\
\hline 6807 & $\mathbf{M}$ & 39 & - & & 250 & - & - & - & - \\
\hline 6811 & $\mathbf{M}$ & 54 & & & - & - & - & - & - \\
\hline 6933 & $\mathbf{F}$ & 17 & - & & - & - & - & - & - \\
\hline 6998 & $\mathbf{F}$ & 52 & & & - & - & - & - & - \\
\hline 7345 & $\mathbf{M}$ & 31 & & & - & & - & - & - \\
\hline 7390 & $\mathbf{M}$ & 36 & - & + & 25,000 & 16 & - & - & - \\
\hline 7476 & $\mathbf{F}$ & 71 & & & - & - & - & - & - \\
\hline 7543 & $\mathbf{F}$ & 40 & - & & - & - & - & - & - \\
\hline 7550 & $\mathbf{M}$ & 22 & - & + & - & - & - & - & - \\
\hline 7587 & $\mathbf{F}$ & 31 & - & & - & - & - & - & - \\
\hline 7720 & F & 50 & & & - & - & & & \\
\hline 7780 & $\mathbf{F}$ & 75 & & & & & & & \\
\hline 7781 & $\mathbf{F}$ & 40 & & & - & - & - & - & \\
\hline 7855 & $\mathbf{F}$ & 17 & & & - & - & - & - & \\
\hline RI. 1 & $\mathbf{M}$ & 67 & & & - & - & - & - & - \\
\hline RI. 2 & $\mathbf{M}$ & 66 & & & - & - & - & - & - \\
\hline \multicolumn{2}{|c|}{ Positive } & & 2 & & \multicolumn{2}{|c|}{10} & \multicolumn{2}{|c|}{$J$} & $\mathbf{0}$ \\
\hline \multicolumn{2}{|l|}{ Total } & & 48 & & \multicolumn{2}{|c|}{39} & \multicolumn{2}{|c|}{38} & 36 \\
\hline
\end{tabular}

$\begin{array}{ll}16 & - \\ - & - \\ - & -\end{array}$

$-$

-

\section{- Arthritis}

Previous thyrotoxic\&્\&

Previous thyrotoxic 8 sis ? Previous thyrotoxigos

Glycosuria

Slightly thyrotoxic $\overrightarrow{\omega_{3}}$

suria

? Thyrotoxic

Lymphadenopathy

Previous thyrotoxicesjs

Thyrotoxicosis, glyces

raised protein in

? Previous thyrotoxidb

Severe thyrotoxidss?;

vious mucous coftis

Fits, Raynaud's \&nđro

Fits

Raynaud's syndrong,

dison's disease ( $B B$

Arthritis

Pernicious anaer

moto's disease a

Slight thyrotoxicesis-

Epilepsy, previous toxicosis

? Previous thyrotox

Hypothyroid, asthno

Hepatitis

Glycosuria

Glycosuria

Penicillin allergy

Raynaud's syndrome

Hashimoto's disease

Arthritis

Raynaud's syndrome

rotoxicosis

Asthma

Pernicious anaemia 0

Severe thyrotoxicosis

Non-toxic goitre 
all but one of the arthritic cases, one case of cutaneous lupus erythematosus, and three cases without evidence of joint involvement. Strauss (1962) found no evidence of antinuclear factor against skeletal muscle-cell nuclei but Beutner et al. (1962) and Feltkamp et al. (1963a and b) reported its presence. The incidence of positive results against muscle nuclei is not recorded but, using human leucocytes as antigen, Feltkamp et al. (1963a) found antinuclear factor in 15 of 111 cases $(13.5 \%)$. Antinuclear factor was not detected in any of 70 normal controls (type unspecified). In a personal series of 40 cases of myasthenia gravis the antinuclear factor against human leucocytes was detected in eight. No L.E. cells were detected. (The series is additional to the 440 cases described by Simpson (1960) in which one patient had L.E. cells in her blood.) The tests were performed on human leucocytes according to the technique of Alexander, Bremner, and Duthie (1960) who found $4 \%$ positives in 580 controls (healthy young blood donors of both sexes). The cases relevant to the present paper are summarized in Table III.

The original series (Simpson, 1960) contained one

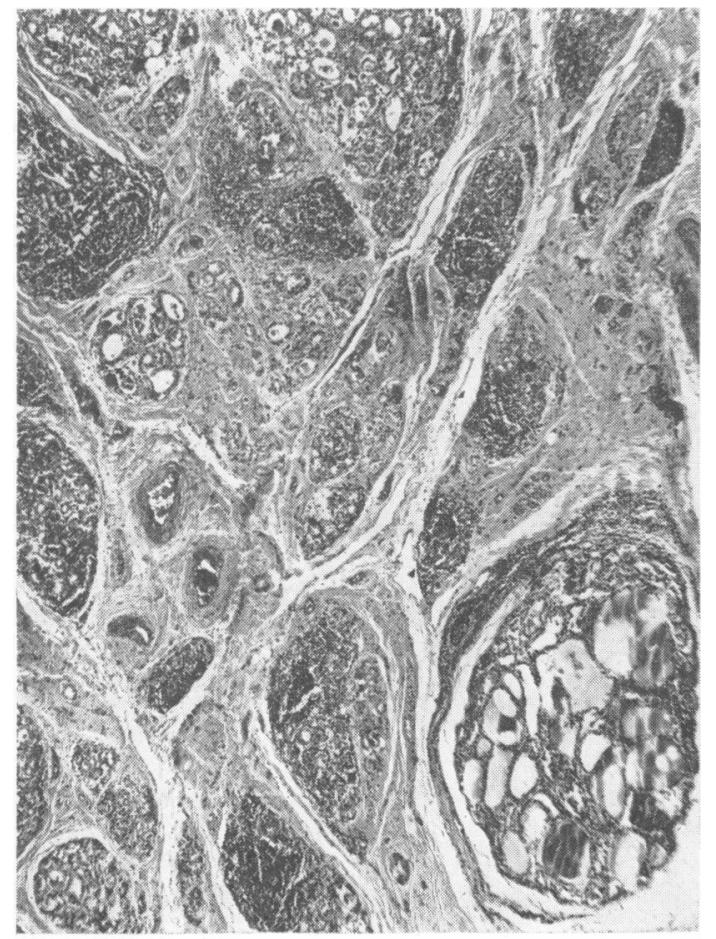

FIG. $2 \mathrm{a}$. case of pure red-cell aplasia. Holborow, Asherson, Johnson, Barnes, and Carmichael (1963) report a positive antinuclear factor test in a case of this disorder associated with a thymoma. There were four cases of pernicious anaemia in the earlier report and this has now increased to nine (Table I) Red-cell aplasia has been associated with myasthenia gravis and thymomas by several authors but no correlation has been described between myasthenia gravis and pernicious anaemia though it has been mentioned in one report (Rowland, Hoefer, Aranow, and Merritt, 1956). My own cases are described in another paper (in preparation). It has recently been suggested that pernicious anaemia is associated with an immunological disorder with production of organspecific antibody to intrinsic factor and to the parietal cells of the stomach (Schwartz, 1960; Irvine, Davies, Delamore, and Williams, Wynn 1962; Taylor, Roitt, Doniach, Couchman, and Shapland, 1962). In the present series of myasthenic patients, antibody active against human stomach was detected in three of 35 cases of which one had pernicious anaemia. With the method used positive results are obtained in $8 \%$ of middle-aged female blood donors

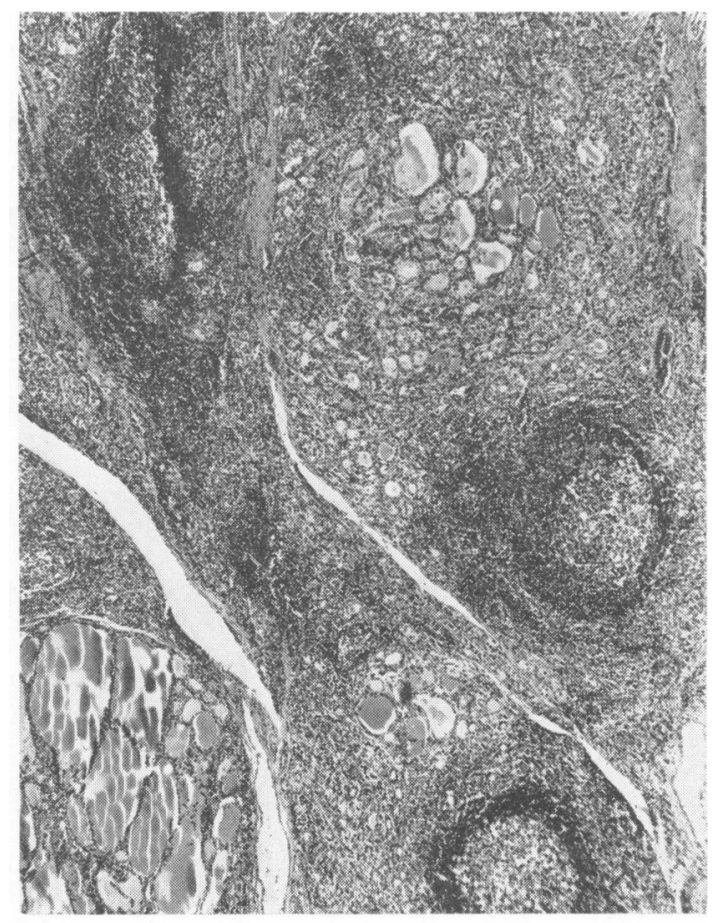

FIG. 2b.

FIG. 2a. Section of thyroid from case MN 7390 showing lymphadenoid goitre which was unsuspected during life. $\times 30$ FIG. 2b. Lymphadenoid goitre from a case of thymoma with myasthenia gravis. $\times 30$ 
(Irvine, 1964). The other patients with pernicious anaemia listed in the full series (Table I) are no longer available for immunological studies. It has also been reported recently that pernicious anaemia may be associated with rheumatoid arthritis (Partridge and Duthie, 1963), with autoimmune thyroiditis (Irvine et al., 1962; Taylor et al., 1962; Markson and Moore, 1962), with thyrotoxicosis and systemic lupus erythematosus (Doniach, Roitt, and Taylor, 1963), and with diabetes mellitus (Arapakis, Bock, Williams, and Witts, 1963; Beckett and Matthews, 1962). There is thus an overlap between several diseases associated with abnormal immunological reactions and to these myasthenia gravis should now be added.

The relationship between thyrotoxicosis and myasthenia gravis has been known for many years but Simpson (1960) showed that the relationship was indirect and could be genetic. Many of the cases previously described have shown diffuse lymphoid changes in the thyroid. Case MN 5503 (Table III) was found to have thyroiditis of Hashimoto type at necropsy. This was unsuspected during life until thyroid antibodies were found in her blood. One case of myasthenia with thymoma had Hashimoto's struma (not included in the Table) (Fig. 2). A clinical diagnosis of Hashimoto's disease was made in the following case (MN 7390). A point of special interest is that Hashimoto's disease developed five to seven years after thymectomy.

J. McD (male) was found to have active pulmonary tuberculosis and at the same time he developed ptosis, diplopia, dysphagia, and weakness of the arms in 1943 when aged 19. Myasthenia gravis was diagnosed and treated with neostigmine until 1955 when thymectomy was carried out by Mr. Paterson Brown in Edinburgh Royal Infirmary. Neostigmine requirements were reduced from 25 to 10 to 15 tablets daily.

From 1960 he complained at intervals of abdominal pain, sweating, and tiredness, which were alleviated by regulation of the dosage of neostigmine and pyridostigmine. During one such episode he was admitted to Inverness Royal Infirmary where it was noted that he had a diffuse goitre and pigmentation of the face (Fig. 3). He was complaining of tiredness and dyspnoea which were not improved by regulation of dosage and were not apparently due to reactivation of tuberculosis. He was overweight and showed no clinical evidence of thyrotoxicosis.

A radio-iodine uptake test gave a T.P.I. of 1.6 and the protein-bound iodine was $1.4 \mathrm{mg}$. per $100 \mathrm{ml}$. Serum cholesterol concentration was $200 \mathrm{mg}$. per $100 \mathrm{ml}$. Antibody titres against thyroid tissue were T.C.H. $1 / 2,500,000$; C.F.T. 1/256; precipitin test positive within 24 hours. The zinc sulphate turbidity was 14.4 units and thymol turbidity $\mathbf{8 \cdot 2}$ units. A diagnosis of Hashimoto's disease was made and treatment started with 1-thyroxine (0.1 mg. daily) in February 1963. He was

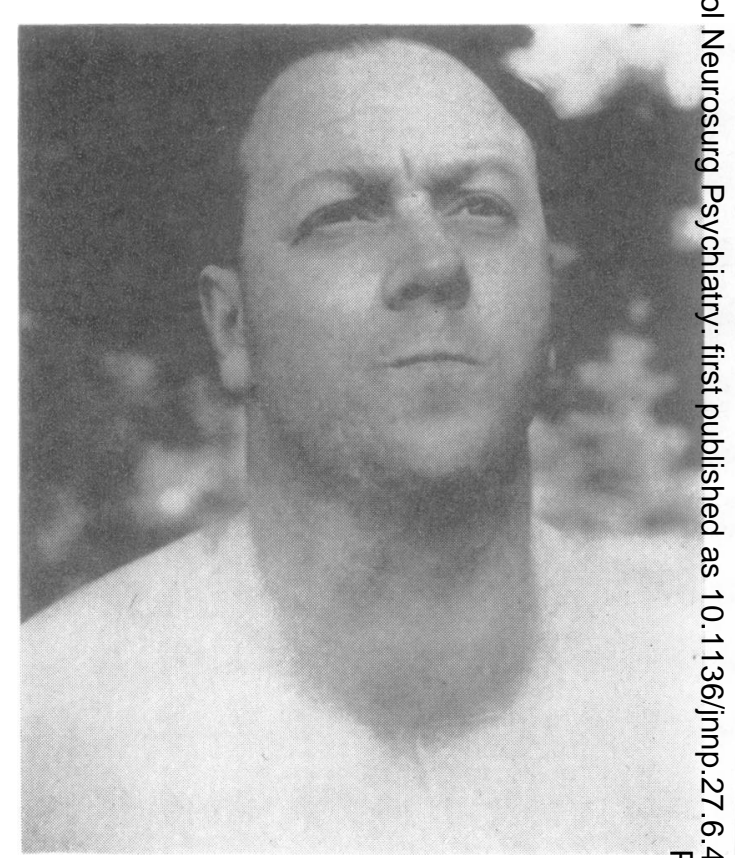

FIG. 3. Myasthenic patient who developed Hashimo disease after thymectomy.

admitted to the Neurological Unit in July 1963. Ffe E.S.R. was 70 to $85 \mathrm{~mm}$. in the first hour. No L.E. ce्ell were found in his blood and antinuclear factor was oof detected (Dr. W. R. M. Alexander). Antibody ti e against thyroid were estimated by Dr. W. J. Irvingas T.C.H. $1 / 25,000$, C.F.T. $1 / 16$. No antibodies acEive against gastric or liver tissues were found. Serum electro phoresis showed increased gamma globulin, thymol turbidity was 5 units, and the cephalin-cholesteros flocculation test was positive. The pulmonary tubercus losis was considered to be inactive. No mediastinal tumous could be detected by radiology. Myasthenia was wey controlled by pyridostigmine $60 \mathrm{mg}$. t.d.s. and neostig mine $15 \mathrm{mg}$. t.d.s. (alternating) and ephedrine gr. $\frac{1}{2}$ t.d.s. Persisting tiredness was considered to be caused b Hashimoto's disease.

Thyroid antibodies have been present in 10 of 38 cases examined in this series by the method describet by Irvine (1964). Six of the positive reactors have had confirmed or suspected thyrotoxicosis at some time in the past and another four cases with a similar. history have not had a significant level of antithyroid substances in their serum. The others shown i Table III have not been examined for thyroid antis bodies. Van der Geld et al. (1963) found antithyroid antibodies in 36 of 111 cases of myasthenia gravis.

No detailed studies have yet been made on the relationship with diabetes mellitus. This may be coincidental but is worth further study since therey 
also appears to be a familial relationship between the two conditions (Simpson, 1960). Other diseases believed to be autoimmune in type have occasionally been associated with myasthenia gravis. Raynaud's syndrome present in more than $2 \%$ of myasthenic patients (Simpson, 1960) may be caused by autoagglutinins in the blood (Forbes, 1947). Ulcerative colitis and hepatic cirrhosis were associated with systemic lupus erythematosus which followed thymectomy for myasthenia gravis in a patient recently reported by Alarcon-Segovia, Galbraith, Maldonado, and Howard (1963). I have seen two myasthenic patients with acute hepatitis and two with acute haemolytic anaemia. In each instance it was considered that the liver or blood disorder was due to the toxic effect of a drug such as chlorpromazine or P.A.M. (Simpson, 1961) but cases recorded in other series are listed in Table I. One patient (MN 5409), who had had myasthenia gravis for 22 years, developed Addison's disease which caused his death. At necropsy it was shown that both adrenal glands were caseous owing to tuberculous infection. No abnormal antibodies were found in his serum.

\section{DISCUSSION}

The evidence gathered together in this paper supports the hypothesis that myasthenia gravis is associated with disturbed antigen-antibody reactions but demonstrates that there may be several organ-specific antibodies present and that there is a clinical and serological overlap with many other autoimmune disorders. Antibodies against muscle fibres are rare except in the presence of a thymic tumour and may not account for the defect of neuromuscular transmission. Some of the permanent weakness found in severe myasthenia, notably in association with a thymoma, may be due to this type of reaction. The possibility of a more localized end-plate reaction remains unconfirmed. The multiplicity of antibodies makes it unlikely that each organ is 'leaking' antigen which then 'instructs' the reticuloendothelial system to form appropriate antibody. It is more probable that the antibody-producing mechanism is producing proteins of which some react with various tissues. There can now be little doubt that the thymus plays a key role in the regulation of antibody production at least in foetal life but the persistence of myasthenia after thymectomy or the development after thymectomy of myasthenia gravis (Green and Booth, 1958), thyrotoxicosis (personal experience), ulcerative colitis, and systemic lupus erythematosus (AlarćonSegovia et al., 1963) make it certain that the thymus is not necessary for the continuation of the disease or for the subsequent development of autoimmune disorders. The present paper records a case of Hashimoto's disease which probably occurred at least five years after thymectomy.

The observation that thymectomy is most beneficial if performed within five to seven years of the onset of myasthenia gravis might imply that it is an essential element at first but that other parts of the reticuloendothelial system may then continue to produce autoantibodies without its presence (Simpson, 1958, 1960). Nothing is known of the nature of the possible changes of immunological tolerance. Burnet (1962a) discusses various hypotheses involving failure of a homoeostatic control of the thymus and White and Marshall (1962) suggest a breakdown of a blood-thymus barrier. Since the first part of the writer's hypothesis has proved so acceptable it might not be inappropriate to draw attention to the other part. A study of the personal and family histories of 440 patients with myasthenia gravis suggested that the altered immunological tolerance might be due to a genetic factor acting on the thymus through the pituitary gland. This may provide the intrinsic (nonimmunological) stimulus to the thymus or the homoeostatic mechanism required by Burnet's theory. Burnet (1962a) proposes that the thymus is primarily concerned with the maintenance of the chemical integrity of the body, including the mechanism of specific protein synthesis. He suggests that the development of the immunological competence of the body is part of the process of morphological and functional differentiation of the embryo and young animal as previously postulated by Simpson (1960). Weiss (1950) and Burwell (1963) have developed alternative theories of control by the reticuloendothelial system of cellular growth and differentiation. If my further suggestion that this mechanism is controlled by the pituitary gland is as fruitful as the rest of the hypothesis it would open up a new field of experimental biology.

\section{SUMMARY}

The author's hypothesis of an autoimmune mechanism in myasthenia gravis is summarized and further evidence reviewed. A high incidence of thyroid disorders, pernicious anaemia, and a rheumatoid type of arthritis is reported. Many cases had antinuclear factor and others had antibodies in their serum specific against thyroid or gastric tissue. No significant antimuscular activity was found in a small sample and it is suggested that this disagreement with other workers is due to absence of thymoma in the cases examined. The occurrence of Hashimoto's disease in a myasthenic patient is recorded. This is the first report of the association and also of the occurrence of Hashimoto's disease in a patient without 
a thymus. A hormonal homoeostatic mechanism for the thymus is suggested.

I am grateful to the Medical Committee of the National Hospital, Queen Square, London, for permission to investigate the London cases, to Dr. W. Lancaster of Inverness Royal Infirmary for referring the patient with Hashimoto's disease, and to Drs. W. R. M. Alexander, J. R. Anderson, and W. J. Irvine for the immunological studies. Dr. A. F. J. Maloney kindly provided the histological studies.

\section{ADDENDUM}

Since this paper was written Daly and Jackson (1964) have reported a case of myasthenia gravis associated with Hashimoto's disease. An additional case in the author's series has been found at necropsy. As no antibody studies were carried out this case is not included in Tables I to III.

\section{REFERENCES}

Alarčon-Segovia, D., Galbraith, R. F., Maldonado, J. E., and Howard, F. M., Jr. (1963). Lancet, 2, 662.

Alexander, W. R. M., Bremner, J. M., and Duthie, J. J. R. (1960). Ann. rheum. Dis., 19, 338.

Arapakis, G., Bock, O. A. A., Williams, D. L., and Witts, L. J. (1963). Brit. med. J., 1, 159.

Beckett, A. G., and Matthews, D. M. (1962) Clin. Sci., 23, 361

Beutner, E. H., Witebsky, E., Ricken, D., and Adler, R. H. (1962). J. Amer. med. Ass. 182, 46.

Burnet, F. M. (1962a). Aust. Ann. Med., 11, 79.

(1962b). Proc. roy. Soc. Med., 55, 619.

Burwell, R. G. (1963). Lancet, $2,69$.

Daly, J. J., and Jackson, E. (1964). Brit. med. J., 1, 748. Doniach, D., Roitt, I. M., and Taylor, K. B. (1963). Brit. med. J., $\frac{\mathrm{O}}{\frac{1}{2}}$

Feltkamp, T. E. W., Geld, H. van der, Kruyff, K., and Oosterhi田. H. J. G. H. (1963a). Lancet, 1, 667. ,$- \frac{1}{8,317 .}$, and Oosterhuis, H. J. G. H. (1963b). Vox Sang. (Based,

Forbes, G. B. (1947). Brit, med. J., 1, 598.

Geld, H. van der, Feltkamp, T. E. W., Loghem, J. J. van, Oosterhuiv, H. J. G. H., and Biemond, A. (1963). Lancet, 2. 373.

- and Oosterhuis, H. J. G. H. (1963). Vox Sang. (Basel), 8, $19 \bigotimes$

Green, R. A., and Booth, C. B. (1958). Amer. J. Med., 25, 293.

Harvey, A. M., Shulman, L. E., Tumulty, P. A., Conley, C. L., am Schoenrich, E. H. (1954). Medicine (Baltimore), 33, 291.

Holborow, E. J., Asherson, G. L., Johnson, G. D., Barnes, R. D. S and Carmichael, D. S. (1963). Brit med. J., 1, 656.

Irvine, W. J. (1964). Ann. N.Y. Acad. Sci., in the press. Davies, S. H., Delamore, I. W., and Williams, A. Wynn (1969. Brit. med. J., 2, 454.

Markson, J. L., and Moore, J. M. (1962). Lancet, 2, 1240.

Marshall, A. H. E., and White, R. G. (1961) Ibid., 1, 1030

Miller, J. F. A. P. (1961). Ibid., 2, 748

- (1963). Brit. med. J., 2, 459.

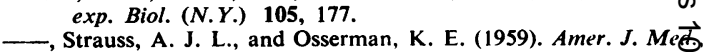
26, 394.

Partridge, R. E. H., and Duthie, J. J. R. (1963). Brit. Med. J., 1, 89.

Rowland, L. P., Hoefer, P. F. A., Aranow, H. Jr., and Merritt, H. (1956). Neurology (Minneap.), 6, 307.

Schwartz, M. (1960). Lancet, 2, 1263.

Simpson, J. A. (1958), Brain, 81, 112

- (1960). Scot. med. J., 5, 419.

(1961). Communication to Brit. Pharmacol. Soc., 14th July

Smithers, D. W. (1959). J. Fac. Radiol. (Lond.), 10, 3.

Strauss, A. J. L. (1962). Lancet, 2, 351. and Osserman, K. E. (1960). Proc. Soc. exp. Biol. (N.Y. 184.

Taylor, K. B., Roitt, I. M., Doniach, D., Couchman, K. G., and 杂apland, C. (1962). Brit. med. J., $2,1347$.

Weiss, P. (1950). Quart. Rev. Biol., 25, 177.

White, R. G., and Marshall, A. H. E. (1962). Lancet, 2, 120. 